Research Article

\title{
Incidence of Erythema Multiforme among Patients with ORF Disease in Al-Kindy Teaching Hospital
}

\author{
lnas O Kadhim', Mohammed Y Abbas', Ali H Hafedh \\ ${ }^{1}$ Merjan Medical City, Babylon Health Directorate, Iraq. \\ ${ }^{2}$ Baghdad University Alkindy College of Medicine, Mohamed Al-Qasim St, Baghdad, Iraq. \\ ${ }^{3}$ Alkindy Teaching Hospital, Baghdad, Iraq. \\ DOI: https://doi.org/10.24321/0019.5138.202173
}

\section{I $\quad \mathbf{N} \quad \mathbf{F} \quad \mathbf{O}$}

\section{Corresponding Author:}

Inas O Kadhim, Merjan Medical City, Babylon Health Directorate, Iraq.

E-mail Id:

drinass87@gmail.com

Orcid Id:

https://orcid.org/0000-0003-4443-2334

How to cite this article:

Kadhim IO, Abbas MY, Hafedh AH. Incidence of Erythema Multiforme among Patients with ORF Disease in Al-Kindy Teaching Hospital. J Commun Dis. 2021;53(4):48-53.

Date of Submission: 2021-09-10

Date of Acceptance: 2021-10-03

\section{$\begin{array}{lllllllllll}\mathbf{A} & \mathbf{B} & \mathbf{S} & \mathbf{T} & \mathbf{R} & \mathbf{A} & \mathbf{C} & \mathbf{T}\end{array}$}

Background: ORF virus has a worldwide distribution among sheep and goats. The hypersensitivity reaction, erythema multiforme (EM) is a known complication of ORF infection in humans; however, its occurrence is poorly understood and has not been extensively reviewed.

Aims of the Study: To assess the incidence of EM among patients with ORF infection and to find the association of EM incidence to age, gender, and occupation of the patients.

Method: A cross-sectional study of analytic design was conducted between 1st January 2018 and 31st December 2018 at Al-Kindy Teaching Hospital. Thirty cases of age ranging from 16 to 65 years who were clinically confirmed with ORF with and without EM eruption were included in this study. Data related to age, gender, occupation, complete clinical history, time of getting ORF infection and EM eruption was collected.

Results: The finding of the current study showed that the mean age of studied sample was $36.1 \pm 9.1,19(63.3 \%)$ participants were less than 40 years of age, $24(80 \%)$ were female, $24(80 \%)$ were housewives, and $9(30 \%)$ ORF patients were presented with EM. 4 (44.4\%) patients got EM infection in the first week of ORF infection and $3(33.3 \%)$ in the 2 nd week. No significant association ( $p \geq 0.005$ for all) was found between the status of EM and age category, gender and occupation of the patients.

Conclusion: We could conclude that the incidence of EM was relatively high among patients who had ORF infection.

Keywords: Incidence, Erythema Multiforme, ORF Disease, Al-Kindy Teaching Hospital 


\section{Introduction}

Erythema multiforme (EM) is an acute, self-limiting but often relapsing, mucocutaneous inflammatory condition. It is considered to be a hypersensitivity reaction that is associated with certain infections, vaccinations, and, less commonly, medications. In general, the lesions of EM cover $<10 \%$ of the total body surface area. Mild symptoms of an upper respiratory infection, including low-grade fever, can sometimes be noted prior to and at the start of an episode of EM. Orolabial lesions are noted in two-thirds of patients; while $40.9 \%$ of cases have oral lesions alone. Erosions, blisters, and crusts can be noted in any of the mucous membranes and are typically painful and tender. ${ }^{1}$ EM is reported worldwide without any ethnic predilection. It occurs at any age, more frequently in young adults. The average age of occurrence is between 20 and 30 years, and $20 \%$ of cases occur in children. Erythema multiforme is currently more common in younger males (male-tofemale ratio in the range of 3:2 to 2:1) (mainly second to fourth decades, but can include children and adolescents) $(20 \%){ }^{2}$ The aetiology of EM is still unclear to this day. It is considered as a reaction against certain microorganisms, radiotherapy, systemic diseases, malignancy, and food or drug allergy. ${ }^{3}$ Though HSV type 1 is the most commonly associated cause, HSV type 2 can also induce EM. ${ }^{4}$ Drugassociated EM is reported in less than $10 \%$ of cases. Although numerous causative drugs have been identified, the most common disease-inducing medications are nonsteroidal anti-inflammatory drugs, sulfonamides, antiepileptic, and antibiotics. Laboratory evaluation and histopathology may assist in confirming the diagnosis, determining the causative factor and also excluding other diseases in the differential diagnosis. Although histopathologic changes are not always diagnostic of EM, they can be helpful in excluding other disorders. Similarly, although no specific DIF findings of EM exist, performing a DIF study of perilesional skin can rule out autoimmune bullous disease if that is considered in the differential diagnosis. Indirect immunofluorescence (IDIF) testing can also be useful in making a diagnosis of autoimmune bullous disease. ${ }^{5}$ ORF is a mucocutaneous disease caused by double-stranded DNA parapoxvirus that is also known as sheep pox, ecthyma contagiosum, and contagious pustular dermatitis. Transmission to humans occurs when damaged skin comes into contact with infected sheep, goat saliva, or their dead bodies. The incubation period varies from 3 to 10 days and then single or multiple lesions evolve. At the onset of the disease, primary lesions are papules that gradually progress to nodular lesions. The nodules change into tubercules or crusted form within 4-6 weeks. The lesions may be complicated by lymphangitis or secondary bacterial infection but systemic complications such as erythema multiforme, maculopapular rash, and generalised lymphadenopathy are rare. ${ }^{6}$ Differential diagnoses of ORF include pyoderma, herpetic whitlow, cowpox, cat-scratch disease, anthrax, tularemia, tuberculosis, other mycobacterial infections, syphilis, sportrichosis, keratoacanthoma, and pyogenic granuloma. Diagnosis of ORF is usually based on clinical findings and history of exposure of non-intact skin to contaminated sheep, goat saliva, or their dead bodies. ${ }^{7,8}$ This study was conducted to assess the incidence of EM among patients with ORF infection and find the association of EM incidence to age, gender and occupation of the patients.

\section{Method}

A cross-sectional study of analytic design, this study was carried out during the period from 1st January 2018 to 31st December 2018 at Al-Kindy Teaching Hospital. A convenience sample of 30 patients of age ranging from 16 to 65 years who were clinically confirmed with ORF was considered for the study. The data were collected from thirty patients with clinically confirmed ORF with or without EM who attended outpatient clinics of Al-Kindy Teaching Hospital via a direct interview with the patients. The collected data were related to age, gender, occupation, clinical history regarding infection, drugs history, and any chronic illness especially the connective tissue disease, time of onset of ORF and EM, status of EM (first attack or recurrent), and prescribed medications for ORF. Topical steroid and antihistamines were prescribed for the patients and followed up for six weeks.

\section{Inclusion Criteria}

Any patient of any age and any gender with ORF.

\section{Exclusion Criteria}

Patients with recurrent attacks of EM, patients on immunosuppressive medications, patients with EM and a history of drug intake, history of pregnancy, radiotherapy or insect bite, patients with oral or genital herpes.

The analysis of data was carried out using SPSS version 23. Number and percentage were used to represent the categorical data. Chi-square test and linear regression were used to confirm significance. Statistical significance was considered whenever the P-value was less than 0.05 . Approval was obtained from concerned authorities to carry out the study in January 2018 and consent was obtained from the participants. Difficulty in obtaining an accurate and complete clinical history, small sample size and short duration of study are the limitations of this study.

\section{Results}

The finding of the current study showed that the mean age of the studied sample was $36.1 \pm 9.1$. The results revealed that 19 (63.3\%) participants were less than 40 years of age, $24(80 \%)$ were female, and $24(80 \%)$ were homemakers. The results of this study demonstrated that $9(30 \%)$ ORF patients were presented with EM. The results revealed that 
19 (63.3\%) patients had ORF on the left hand, 8 (26.7\%) on the right hand, and $3(10 \%)$ had ORF on both hands. About two-thirds (70\%) of patients had one lesion of ORF, 7 $(23.3 \%)$ had two lesions, and just $2(6.7 \%)$ had three lesions of ORF. The majority of cases of EM (88.9\%) were of acral type and only one patient had EM of generalised form as displayed in Table 1.

Table I.Sociodemographic and Other Data of Study Participants

\begin{tabular}{|c|c|c|c|}
\hline \multicolumn{2}{|c|}{ Variables } & \multirow{2}{*}{$\begin{array}{c}\text { Frequency } \\
19\end{array}$} & \multirow{2}{*}{$\begin{array}{c}\text { Percentage } \\
63.3\end{array}$} \\
\hline Arogroung (unoral & $<40$ & & \\
\hline Age givups (yedis) & $\geq 40$ & 11 & 36.7 \\
\hline \multirow{2}{*}{ Gender } & Female & 24 & 80.0 \\
\hline & Male & 6 & 20.0 \\
\hline \multirow{4}{*}{ Occupation } & Housewife & 24 & 80.0 \\
\hline & Restaurant worker & 2 & 6.7 \\
\hline & Butcher & 2 & 6.7 \\
\hline & Others & 2 & 6.7 \\
\hline \multirow{2}{*}{ Incidence of EM } & Yes & 9 & 30 \\
\hline & No & 21 & 70 \\
\hline \multirow{3}{*}{ Site of ORF } & $\mathrm{LH}$ & 19 & 63.3 \\
\hline & $\mathrm{RH}$ & 8 & 26.7 \\
\hline & $\mathrm{RH} \& \mathrm{LH}$ & 3 & 10.0 \\
\hline \multirow{3}{*}{ No. of ORF lesions } & One & 21 & 70.0 \\
\hline & Two & 7 & 23.3 \\
\hline & Three & 2 & 6.7 \\
\hline \multirow{2}{*}{ Type of EM } & Acral & 8 & 88.9 \\
\hline & Generalised & 1 & 11.1 \\
\hline
\end{tabular}

Table 2.Association of EM Incidence and Sociodemographic Characteristics of the Patients and Status of Co-morbid IIIness

\begin{tabular}{|c|c|c|c|c|c|c|}
\hline \multicolumn{6}{|c|}{ Presence of EM } & \multirow{3}{*}{ P-value } \\
\hline & & \multirow{2}{*}{$\begin{array}{l}\text { Yes } \\
\text { No. }\end{array}$} & \multirow[b]{2}{*}{$\%$} & \multicolumn{2}{|c|}{ No } & \\
\hline & & & & No. & $\%$ & \\
\hline \multirow{2}{*}{ Age groups (year) } & $<40$ & 7 & 36.8 & 12 & 63.2 & \multirow{2}{*}{0.2} \\
\hline & $\geq 40$ & 2 & 18.2 & 9 & 81.8 & \\
\hline \multirow{2}{*}{ Sex } & Female & 7 & 29.2 & 17 & 70.8 & \multirow{2}{*}{0.8} \\
\hline & Male & 2 & 33.3 & 4 & 66.7 & \\
\hline \multirow{4}{*}{ Occupation } & Butcher & 0 & 0.0 & 2 & 100.0 & 0.6 \\
\hline & Housewife & 7 & 29.2 & 17 & 70.8 & \\
\hline & Restaurant worker & 1 & 50.0 & 1 & 50.0 & \\
\hline & Others & 1 & 50.0 & 1 & 50.0 & \\
\hline \multirow{2}{*}{ Comorbidity } & Yes & 1 & 50.0 & 1 & 50.0 & 0.2 \\
\hline & No & 8 & 28.6 & 20 & 71.4 & \\
\hline
\end{tabular}

P-value $\leq 0.05$ (significant). 
Table 3.Frequency of Patients according to the Month of ORF Infection, Frequency of Patients according to Annual Quarter, and Frequency of Patients according to Sequence of Time in Weeks of getting EM after ORF

\begin{tabular}{|c|c|c|}
\hline & No. of Patients & $\%$ \\
\hline \multicolumn{3}{|l|}{ Months } \\
\hline October & 10 & 33.3 \\
\hline November & 5 & 16.7 \\
\hline June & 3 & 10.0 \\
\hline May & 3 & 10.0 \\
\hline April & 2 & 6.7 \\
\hline July & 2 & 6.7 \\
\hline March & 2 & 6.7 \\
\hline August & 1 & 3.3 \\
\hline December & 1 & 3.3 \\
\hline September & 1 & 3.3 \\
\hline Total & 30 & 100.0 \\
\hline \multicolumn{3}{|c|}{ Annual Quarter } \\
\hline Autumn & 16 & 53.4 \\
\hline Summer & 4 & 13.3 \\
\hline Spring & 6 & 20.0 \\
\hline Winter & 4 & 13.3 \\
\hline Total & 30 & 100.0 \\
\hline \multicolumn{3}{|c|}{ Sequence of time in weeks } \\
\hline 1 & 4 & 44.4 \\
\hline 2 & 3 & 33.3 \\
\hline 3 & 0 & 0.0 \\
\hline 4 & 2 & 22.3 \\
\hline Total & 30 & 100.0 \\
\hline
\end{tabular}

The highest percentage of patients (33.3\%) got ORF in October followed by November (16.7\%), June (10\%), May $(10 \%)$ and the remainder got the infection on different months of the year. The findings showed that about half of the patients $(16,53.4 \%)$ got ORF infection in the 4 th quarter of the year, $4(13.3 \%)$ got the infection in the 3rd quarter of the year, $6(20 \%)$ in the 2 nd quarter, and $4(13.3 \%)$ in the first quarter of the year. The results showed that 4 (44.4\%) patients got EM infection in the first week of ORF infection, $3(33.3 \%)$ got EM in the 2 nd week of ORF infection, nobody got EM in the 3rd week, and $2(22.3 \%)$ got EM in the 4th week of ORF infection as illustrated in Table 3.

The findings showed there was no significant association ( $p=$ 0.2 ) between age category and status of EM eruption as the results showed that out of 19 patients of age less than 40 years, 7 patients developed EM, and out of 11 patients older than 40 years, 2 patients developed EM so the difference did not reach the significant level. The same non-significant association was reported with gender distribution $(p=0.8)$ and occupation of the patients $(p=0.6)$. The results of the current study showed there was no significant association $(p=0.2)$ between comorbidity statuses in terms of present or absent and status of EM, as the EM was reported with patients who had chronic illnesses and with patients who were free of chronic illnesses as seen in Table 2.

\section{Discussion}

ORF is a proliferative viral skin disease occurring in people who are in contact with sheep, goats, and cattle that are infected. It is caused by parapoxviruses which are doublestranded DNA viruses belonging to the pox viridae family. Erythema multiforme (EM) is an acute, immunological, vesiculobullous disorder that primarily affects the skin and mucous membranes. The exact aetiology of EM is obscure, although, prior infection with herpes simplex virus (HSV) and the intake of certain drugs are the common precipitating factors. ${ }^{9,10}$ Our findings demonstrated that $63.3 \%$ of the patients with ORF were less than 40 years of age and these findings are consistent with the report of the Center for Disease Control and Prevention (CDC) that found that the majority of ORF cases were reported within the third or fourth decade of age. ${ }^{11}$ The results of our study also revealed that the sites of infection were distributed as follows: right hand in 8 patients $(26.7 \%)$, left hand in 19 patients $(63.3 \%)$, and right and left hands in 3 patients (10\%). These results are consistent with Lederman ER and Uzel $\mathrm{G}^{12,13}$ who found that hands are the most common site for ORF infection and the other sites of the body are rarely affected. Uluğ $\mathrm{M}$ et al. also found that out of three patients with ORF in their study, two had lesions on only one hand, whereas one patient had additional lesions on the other hand. The lesions were most commonly located on the dorsal aspect of the fingers. ${ }^{14}$ The higher incidence of ORF on the left hands of the patients in our study can be explained in part by the way of handling meat in the left hand while cutting it with the right hand which makes the left hand more in contact with infected meat. The results of the current study also showed that the female patients who were housewives (80\%) were affected more than male patients and these results might be explained on the basis of the fact that women in our community are concerned more with cooking and hence come into contact with infected meat more than the male subjects. Our findings regarding the gender distribution of infection with ORF are in disagreement with Caravaglio JV who found that ORF infection occurs more commonly in men (70\%) owing to the fact that men are more likely to have occupational exposure (eg, ranching, veterinary medicine, animal slaughter). ${ }^{15}$ Meier $\mathrm{R}$ et al. also reported that the farmers, 
butchers, sheep shearers, and veterinarians are prone to ORF disease. ${ }^{16}$ The results of the current study showed that the incidence of ORF infection was more in October (10 patients, 33.3\%) followed by November (5 patients, $16.7 \%$ ). These two months (October and November) coincided with the hijri month (Muharam) and fall within a month of Eid al-Adha when many Muslims slaughter sheep in these religious feasts. This finding is consistent with Shahmoradi $Z$ et al., Veraldi et al., and the CDC report where they also found and reported that the ORF infection is mostly related with Muslim's practice of Eid al-Adha but they also found that it was also seen with Jewish Passover and Christian Easter celebrations. ${ }^{17}$ Concerning the ORF distribution according to gender and timing with the feast, Sacar et al. found that male preponderance (30.4\%) before the Feast of the Sacrifice, whereas a female preponderance $(32.7 \%)$ was found after the Feast. ${ }^{18}$ Bayındır $Y$ et al. ${ }^{19}$ concluded that the ORF infection tends to occur in the spring and the summer months where they found that all patients who enrolled in their study contracted ORF during these two seasons. The results of our study showed that 9 patients (30\%) who presented with ORF developed EM which is a higher incidence than was reported in previous studies which could be due to higher contact with farm animals and meat in our country. Ghislain $P^{20}$ reported that among patients receiving a diagnosis of ORF, an estimated 7-18\% experience EM. The results of the current study demonstrated that the mean age of the studied sample with ORF was 36.1 years. In addition, our findings revealed that 7 out of 9 patients with EM were less than 40 years of age and these findings are consistent with the finding of the study that was conducted by Yavuz $\mathrm{I} \mathrm{H}$ et al. ${ }^{21}$ where they also found that the mean age of their patients with EM was 36.7 years. It is also consistent with the results of the study that was carried out by Lerch $M$ et al. ${ }^{1}$ who have stated that EM is particularly seen in the second and third decades of life. The current study revealed that 7 of our patients with EM were females and these results are in agreement with the results of Yavuz IH et al. ${ }^{21}$ who had also reported a higher percentage of EM among females (66.7\% of their patients were females). The findings were also consistent with Samim F et al. ${ }^{22}$ who indicated EM is more common in women than men. However, Kondolot et al. reported that there was a male preponderance in their paediatric patients. ${ }^{23}$ The highest percentage of patients (44.4\%) developed EM within the first week of ORF infection and these findings are partially consistent with Aktaş $\mathrm{H}$ et al. ${ }^{24}$ who found that the mean time for erythema multiforme development after ORF infection was 6.7 (range 5-9) days. Azizzadeh M and Coskun $O$ et al. ${ }^{6,24}$ also related EM disease to ORF infection and they found that ORF associated EM typically develops 2-4 weeks after the onset of primary ORF lesion and is characterised by acute onset of symmetrically distributed papules, macules, bullae, and target lesions. According to the findings of previous literature that confirmed the association between EM and herpes viral infection, the association of EM and ORF infection could be explained by the same mechanisms which are thought to be a cell-mediated immune reaction against viral antigens in the lesions. Some studies have stated that the possible mechanisms of ORF induced cutaneous manifestation include virus mimicry of host proteins and alteration of basement membrane proteins by the virus. ${ }^{25}$

\section{Conclusion}

We could conclude that the incidence of EM was relatively high among patients who had ORF infection.

Source of Funding: No source of funding

\section{Conflict of Interest: None}

\section{References}

1. Lerch M, Mainetti C, Beretta-Piccoli BT, Harr T. Current perspectives on erythema multiforme. Clin Rev Allergy Immunol. 2018; 54:177-84. [PubMed] [Google Scholar]

2. Lam NS, Yang YH, Wang LC, Lin YT, Chiang BL. Clinical characteristics of childhood erythema multiforme, Stevens-Johnson syndrome and toxic epidermal necrolysis in Taiwanese children. J Microbiol Immunol Infect. 2004;37(6):366-70. [PubMed] [Google Scholar]

3. Issrani R, Prabhu N. Etiopathogenesis of erythema multiforme - a concise review. Etiopathogenesis of erythema multiforme - a concise review. Adv Dent Oral Health. 2017;5(4):555669. [Google Scholar]

4. Roujeau JC. Erythema multiforme. In: Goldsmith LA, Katz SI, Gilchrest BA, Paller AS Leffell DJ, Wolff K, editors. Fitzpatrick's dermatology in general medicine, 8th ed. New York, NY:McGraw-Hill;2008.

5. Sokumbi O, Wetter DA. Clinical features, diagnosis, and treatment of erythema multiforme: a review for the practicing dermatologist. Int J Dermatol. 2012;51:889902. [PubMed] [Google Scholar]

6. Coskun O, Gul CH, Bilgeturk A, Besirbellioglu BA, Eyigun $\mathrm{CP}$, Coskun O. Human orf complicated with erythema multiforme. Int J Dermatol. 2008;47(12):1333-4. [PubMed] [Google Scholar]

7. Slattery WR, Juckett M, Agger WA, Radi CA, Mitchell T, Striker R. Milkers' nodules complicated by erythema multiforme and graft-versus-host disease after allogeneic hematopoietic stem cell transplantation for multiple myeloma. Clin Infect Dis. 2005;40(7):e63-e6. [PubMed] [Google Scholar]

8. Ozturk P, Sayar H, Karakas T, Akman Y. Erythema multiforme as a result of Orf disease. Acta Dermatovenerol Alp Pannonica Adriat. 2012;21(2):456. [PubMed] [Google Scholar]

9. Aktaş H, Ucmak D, Akkurt ZM, Karlı ş. Erythema 
multiforme developing secondary to Orf disease: ten cases. Turk J Dermatol. 2018;12:149-53. [Google Scholar]

10. Hasan S, Jangra J, Choudhary P, Mishra S. Erythema multiforme: a recent update. Biomed Pharmacol J. 2018;11(1):167-70. [Google Scholar]

11. Centers for Disease Control and Prevention (CDC). Human Orf virus infection from household exposures - United States, 2009-2011. MMWR Morb Mortal Wkly Rep. 2012 Apr 13;61(14):245-8. [PubMed] [Google Scholar]

12. Lederman ER, Austin C, Trevino I, Reynolds MG, Swanson H, Cherry B, Ragsdale J, Dunn J, Meidl S, Zhao H, Li Y, Pue $H$, Damon IK. Orf virus infection in children: clinical characteristics, transmission, diagnostic methods, and future therapeutics. Pediatr Infect Dis. 2007;26:740-4. [PubMed] [Google Scholar]

13. Uzel M, Sasmaz S, Bakaris S, Cetinus E, Bilgic E, Karaoguz A, Ozkul A, Arican O. A viral infection of the hand commonly seen after the feast of sacrifice: human orf (orf of the hand). Epidemiol Infect. 2005;133(4):653-7. [PubMed] [Google Scholar]

14. Uluğ $M$, Ürer MS, Bilgili ME. A viral infection of the hands: Orf. J Microbiol Infect Dis. 2013;3(1):41-44. [Google Scholar]

15. Caravaglio JV, Khachemoune A. Orf virus infection in humans: a review with a focus on advances in diagnosis and treatment. J Drugs Dermatol. 2017 Jul 1;16(7):6849. [PubMed] [Google Scholar]

16. Meier R, Sommacal A, Stahel A, Grünert J, Hoffmann M. Orf - an orphan disease? JRSM Open. 2015;6:2054270415593718. [PubMed] [Google Scholar]

17. Veraldi S, Nazzaro G, Vaira F, Çuka E. Presentation of orf (ecthyma contagiosum) after sheep slaughtering for religious feasts. Infection. 2014 Aug;42(4):767-9. [PubMed] [Google Scholar]

18. Saçar H, Uyar B, Saçar T, Duran A. Investigation of the complications and incidences of orf disease during and after the Feast of the Sacrifice period. Dermatolog Sinica. 2015;33(4);191-5. [Google Scholar]

19. Bayındır Y, Bayraktar M, Karadağ N, Ozcan H, Kayabas $U$, Otlu B, Durmaz R, Doganay M. Investigation and analysis of a human orf outbreak among people living on the same farm. New Microbiol. 2011;34:37-43. [PubMed] [Google Scholar]

20. Ghislain PD, Dinet Y, Delescluse J. [Orf in urban surroundings and religious practices: a study over a 3-year period]. Ann Dermatol Venereol. 2001;128:88992. French. [PubMed] [Google Scholar]

21. Yavuz IH, Yavuz GÖ, Bilgili SG, Bayram I, Savaş H. Erythema multiforme; sixty six case series with review of literature. East J Med. 2018;23(4):308-12. [Google
Scholar

22. Samim F, Auluck A, Zed C, Williams PM. Erythema multiforme: a review of epidemiology, pathogenesis, clinical features, and treatment. Dent Clin North Am. 2013;57:583-96. [PubMed] [Google Scholar]

23. Kondolot M, Çipe F, Özmen S, Arslan Z. Evaluation of cases with erythema multiforme. Turkhis J Pediatr Dis. 2008;2:5-10.

24. Azizzadeh M. Case report orf followed by erythema multiforme. J Semnan Univ Med Sci. 2007;9:1-2. [Google Scholar]

25. White KP, Zedek DC, White WL, Simpson EL, Hester E, Morrison L, Lazarova Z, Liu D, Scagliarini A, Kurtz SE, White CR Jr, Yancey KB, Blauvelt A. Orf-induced immunobullous disease: a distinct autoimmune blistering disorder. J Am Acad Dermatol. 2008;58:4955. [PubMed] [Google Scholar] 